\title{
Clinics in diagnostic imaging (177)
}

Poh Lye Paul See, MBBS, FRCR

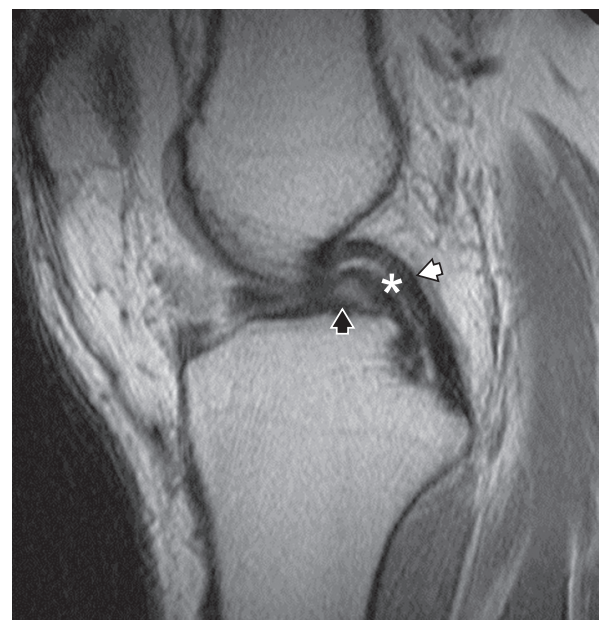

Fig. 1 Sagittal proton density (PD)-weighted fast spin-echo (FSE) MR image of the left knee.
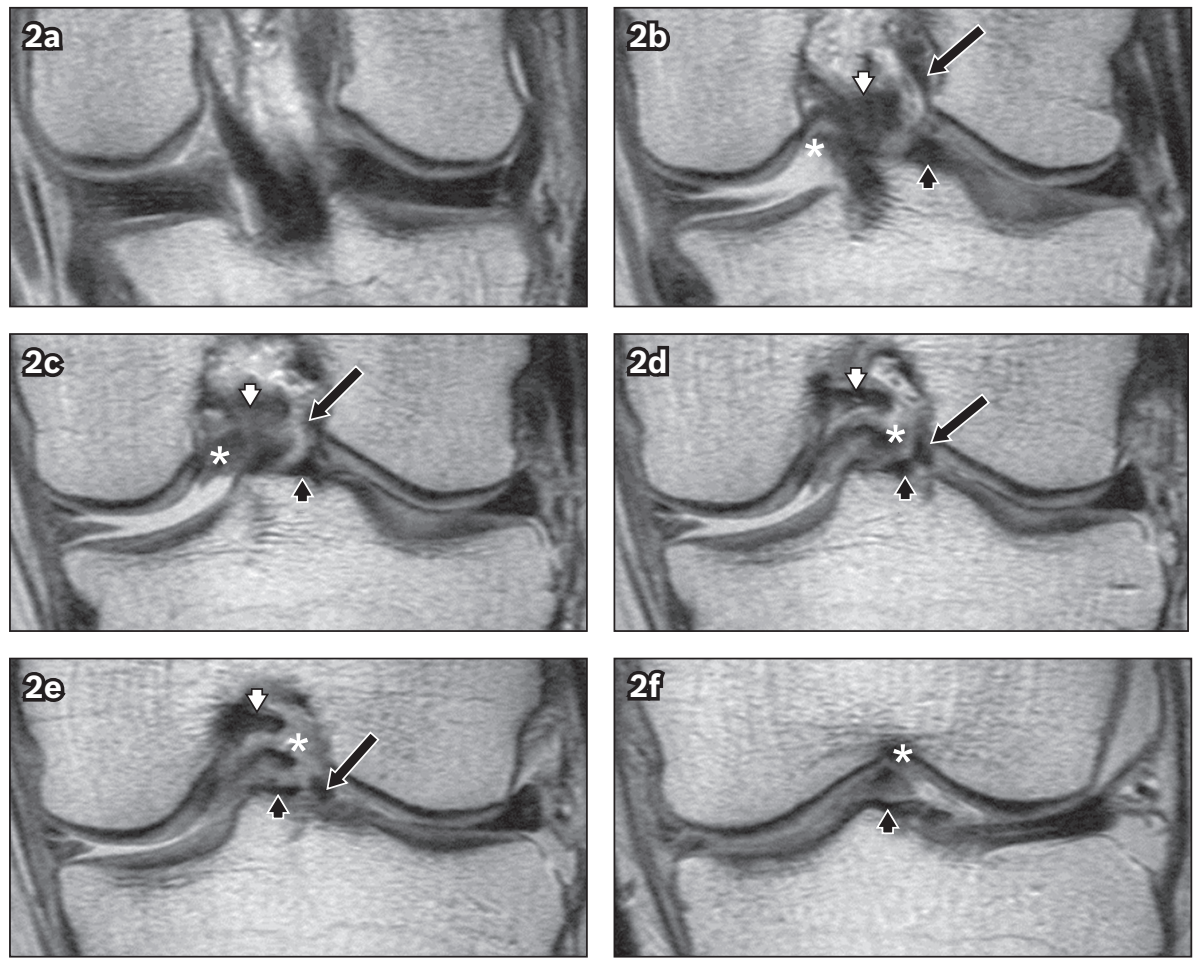

Fig. 2 Serial coronal PD-weighted FSE MR images from the posterior to anterior aspect of the left knee. The medial compartment is on the left side of the images.

\section{CASE PRESENTATION}

A 29-year-old man presented with pain in his left knee. He had twisted it as he turned a corner quickly while going up the stairs, leading to an internal rotation of his femur on his tibia while his knee was in flexion. He had twisted the same knee a few years ago when playing football, with resultant knee pain, instability and occasional locking. He had not sought treatment then, as the pain had subsequently improved, although the other symptoms had persisted. Physical examination revealed no swelling, but the range of motion of the left knee was reduced and the anterior drawer test was positive. Subsequent imaging of the knee revealed largely unremarkable radiographic findings. Magnetic resonance (MR) imaging findings are shown in Figs. 1 and 2. What are the structures within the intercondylar fossa? What is the diagnosis? 


\section{IMAGE INTERPRETATION}

MR images show two additional structures within the intercondylar fossa of the knee besides the two structures usually found in the fossa, namely the anterior cruciate ligament $(\mathrm{ACL})$ and posterior cruciate ligament $(\mathrm{PCL})$. The first is a low-signal-intensity band (* in Figs. 1 \& 2) that runs parallel and anteroinferior to the PCL (white arrowhead in Figs. 1 \& 2) on the midline sagittal (Fig. 1) and coronal (Fig. 2) MR images. This is compatible with the double PCL sign, which is highly specific for a bucket-handle meniscal tear. In addition, there is a further linear structure of low signal intensity (black arrowhead, Figs. 1 \& 2) extending from the posterior horn of the lateral meniscus into the intercondylar fossa, running anteroinferior to the aforementioned structure and located just above the intercondylar eminence of the tibia. It appears to terminate in the expected region of the anterior horn of the medial meniscus. Finally, a high-grade tear of the $\mathrm{ACL}$ (black arrow, Figs. 2b-e) is visible on the images, although it is not well demonstrated.

\section{DIAGNOSIS}

Medial meniscus bucket-handle tear with medial oblique meniscomeniscal (MM) ligament.

\section{CLINICAL COURSE}

Subsequent arthroscopy confirmed all the MR imaging findings. The patient underwent an ACL reconstruction and repair of the medial meniscus bucket-handle tear. He was discharged well after receiving gait training and being issued with crutches. The patient was subsequently followed up by a physiotherapist.

\section{DISCUSSION}

The C-shaped fibrocartilaginous menisci of the knee aid in joint stabilisation and load transmission. Four different types of MM ligaments have been described in the medical literature. ${ }^{(1-3)}$ The most commonly observed of these intermeniscal ligaments is the anterior intermeniscal ligament, with a reported frequency of 58\%, followed by the posterior intermeniscal ligament, with a reported frequency of $1 \%-4 \% .{ }^{(1)}$ The other two variants are the medial and lateral oblique MM ligaments, which are reported at a combined frequency of $1 \%-4 \% .{ }^{(1)}$ Chan and Goldblatt described two other variants extending from the anterior to the posterior horns of the corresponding medial and lateral menisci, respectively, which they termed unilateral MM ligaments. ${ }^{(4)}$ However, these may merely represent ring menisci, a rare congenital variant characterised by a ring shape; the anterior and posterior horns are connected by an inner horn bridge and present on imaging as complete rings of meniscal tissue. ${ }^{(5)}$

Oblique MM ligaments are named based on their anterior attachment site. Fig. 3 diagrammatically presents the medial and lateral oblique MM ligaments, with normal medial and lateral menisci for comparison. The medial oblique MM ligament, as in our case, is attached to the anterior horn of the medial meniscus and posterior horn of the lateral meniscus (Fig. 4). The lateral oblique MM ligament is attached to the anterior horn of the lateral meniscus and posterior horn of the medial meniscus. Both oblique
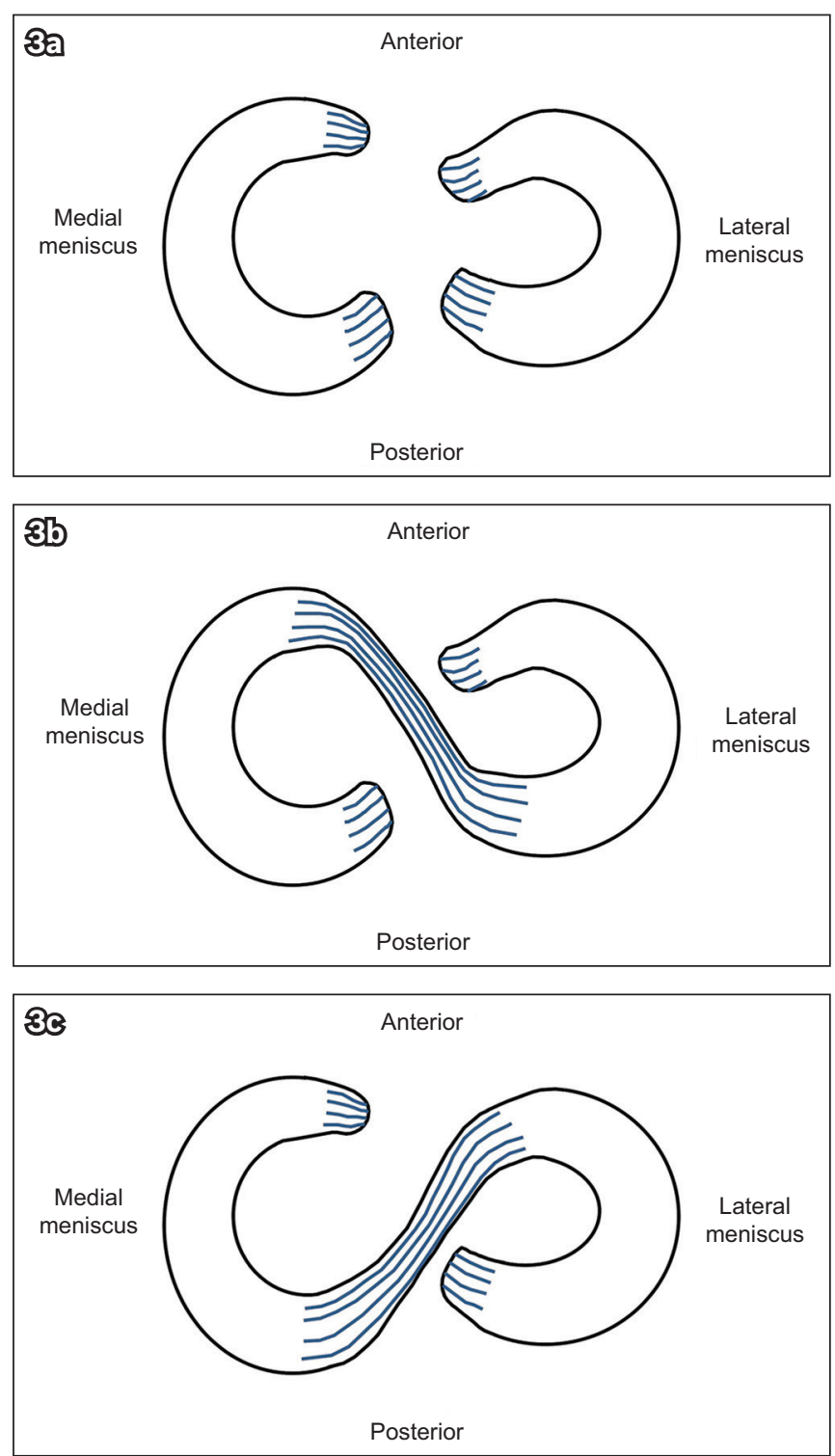

Fig. 3 Line drawings (viewed from above) show (a) the normal menisci and oblique meniscomeniscal (MM) ligament variants; (b) the medial oblique MM ligament attached to the anterior horn of the medial meniscus and the posterior horn of the lateral meniscus; and (c) the lateral oblique MM ligament attached to the anterior horn of the lateral meniscus and the posterior horn of the medial meniscus.

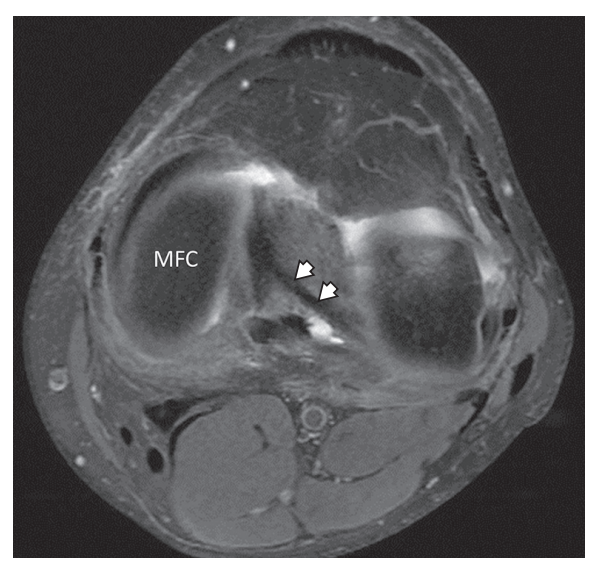

Fig. 4 Axial fat-suppressed PD-weighted FSE MR image of the left knee shows the medial oblique meniscomeniscal ligament (arrowheads) attached to the anterior horn of the medial meniscus and the posterior horn of the lateral meniscus. MFC: medial femoral condyle 

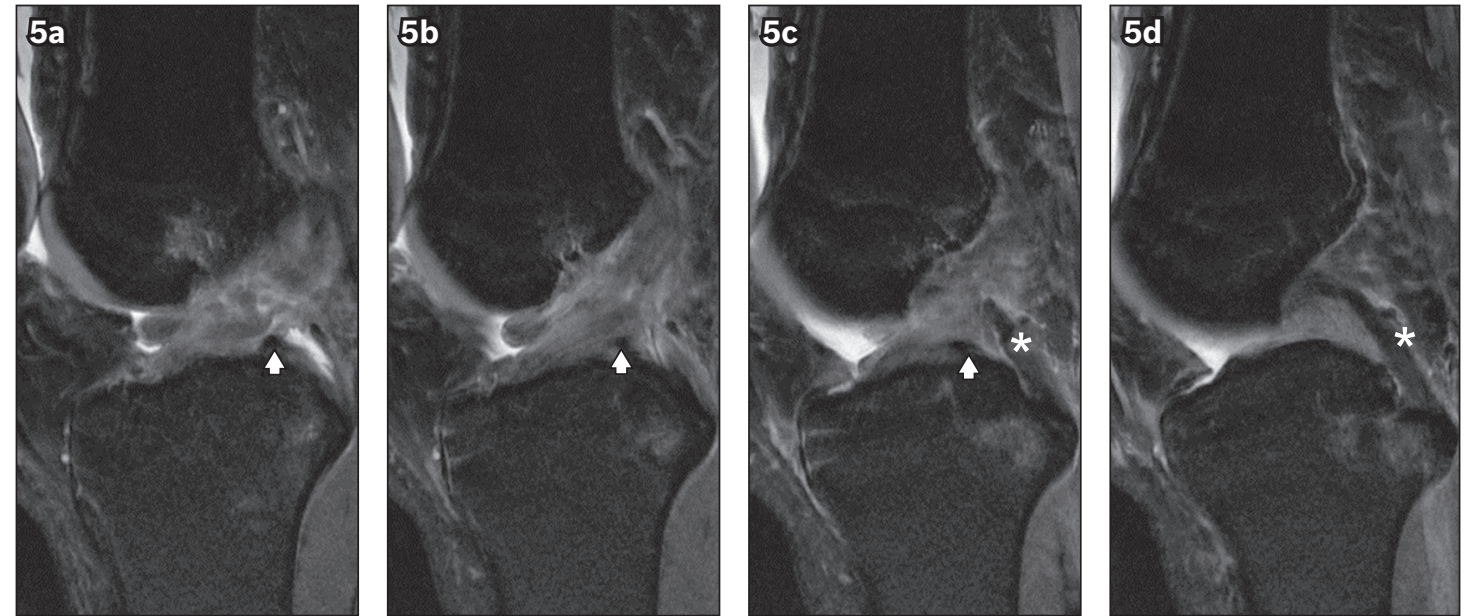

Fig. 5 A separate patient with an oblique meniscomeniscal (MM) ligament without superimposed bucket-handle tear, and a high-grade tear of the anterior cruciate ligament. Serial sagittal fat-suppressed PD-weighted FSE MR images from the lateral to medial aspect of the knee show the course of the medial oblique MM ligament (arrowhead) from the posterior horn of the lateral meniscus to the anterior horn of the medial meniscus. The posterior cruciate ligament $(\mathrm{PCL})$ is intact $\left(^{*}\right)$. There is an apparent double PCL sign, as in Fig. 4c, mimicking a bucket-handle meniscal tear.

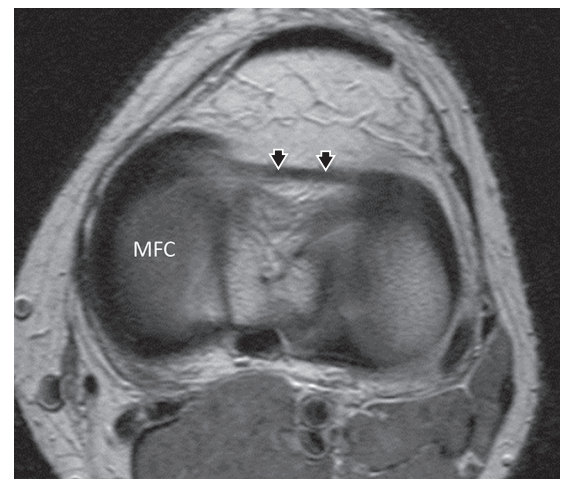

Fig. 6 Axial PD-weighted FSE MR image of the left knee shows an anterior intermeniscal ligament (arrowheads). MFC: medial femoral condyle

MM ligaments traverse the intercondylar fossa, passing between the $\mathrm{ACL}$ and $\mathrm{PCL}$, which are both intra-articular but extrasynovial structures. ${ }^{(2)}$ To my best knowledge, there are no published reports on torn oblique MM ligaments and their imaging features.

The oblique MM ligament may be misinterpreted as a buckethandle tear of the meniscus since it possesses signal intensity that is similar to that of meniscal tissue and also attaches to the meniscus. ${ }^{(6)}$ It can also be mistaken for a torn $\mathrm{ACL}$ or PCL. In our case, the patient did have a bucket-handle tear of the medial meniscus, which accounts for the double PCL sign. However, this rare occurrence of a concurrent oblique MM ligament resulted in an imaging finding that was equivalent to a triple PCL sign (Fig. 1). In a separate patient with an oblique MM ligament without superimposed bucket-handle tear (Fig. 5), the spurious double PCL sign would appear as shown in Fig. 5c.

The double PCL sign in the context of a bucket-handle medial meniscal tear is often seen only in patients with an intact $A C L$, as the intact $A C L$ prevents the flipped fragment from migrating further laterally or not aligning with the $\mathrm{PCL} .{ }^{(7)}$ In a minority of patients, a lateral meniscus bucket-handle tear, in the presence of a torn $\mathrm{ACL}$, may also give rise to a double PCL sign. That we were able to see the double PCL sign in our case, despite the torn $\mathrm{ACL}$, may be due to the limiting presence of the oblique MM ligament and remnant torn ACL fibres. Another potential

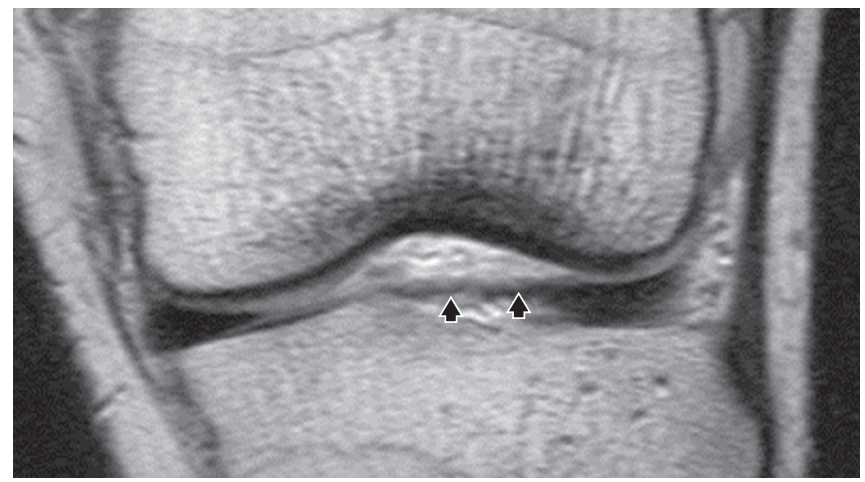

Fig. 7 Coronal PD-weighted FSE MR image shows an anterior intermeniscal ligament (arrowheads).

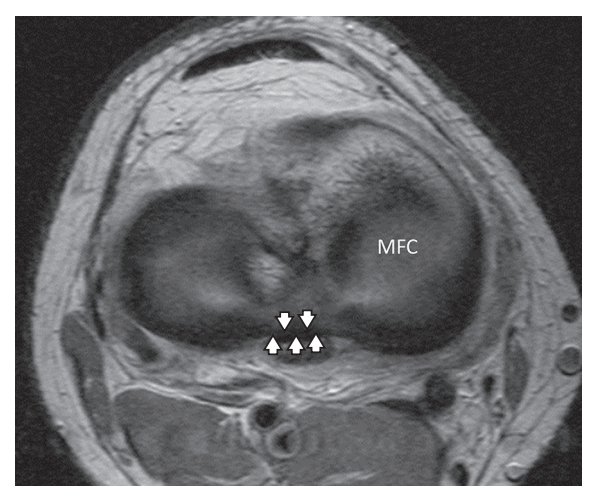

Fig. 8 Axial PD-weighted FSE MR image shows a posterior intermeniscal ligament (arrowheads) attached to the respective posterior horns of the medial and lateral menisci. MFC: medial femoral condyle.

pitfall of the double PCL sign is the presence of a normal anterior meniscofemoral ligament, also known as the ligament of Humphry, which extends from the lateral meniscus posterior horn to the lateral aspect of the medial femoral condyle. This ligament can be differentiated from a bucket-handle fragment by its relatively smaller size and thickness, as well as its extremely close proximity to the PCL. ${ }^{(6)}$ To avoid both of these pitfalls, these ligaments must be carefully traced entirely from their origin to insertion, and corroborated with the normal morphological features of the adjacent menisci. 

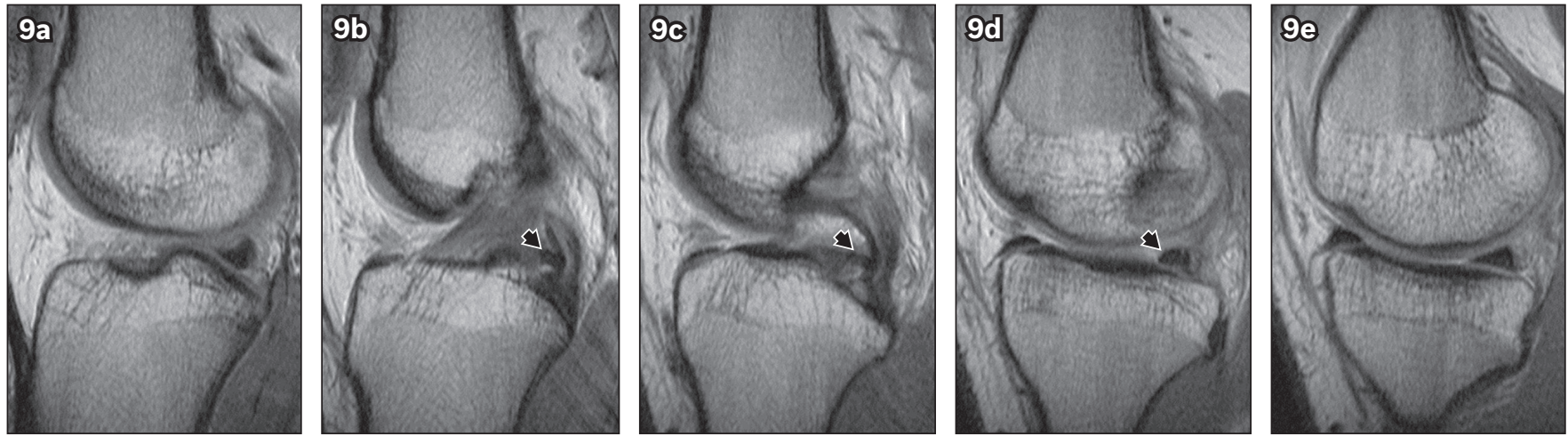

Fig. 9 Serial sagittal PD-weighted FSE MR images from the lateral to medial aspect of the knee show the course of the posterior intermeniscal ligament (arrowhead in $9 b-d$ ) as it attaches to the posterior horns of the medial and lateral menisci. Increased signal intensity at the interface between the ligament and posterior horn of the lateral meniscus mimics a tear (9d). The ligament can also be misinterpreted as a displaced meniscal fragment (9c).

The anterior and posterior intermeniscal ligaments can also mimic tears at their meniscal attachment sites. The anterior intermeniscal ligament is described in Gray's Anatomy as "connecting the anterior convex margin of the lateral meniscus to the anterior end of the medial meniscus." ${ }^{(8)}$ However, Nelson and LaPrade have described three types of insertion: Type I has attachments to the anterior horn of the medial meniscus and anterior margin of the lateral meniscus; Type II has a medial attachment to the anterior margin of the medial meniscus and a lateral attachment to the joint capsule anterior to the lateral meniscus; and Type III has medial and lateral capsular anterior attachments without direct attachments to the anterior horns of either the medial or lateral menisci. ${ }^{(9)}$ Type I, which fits the classic description of primary attachments, is the most common (Figs. 6 \& 7).

Regardless of insertion type, the region of confluence of the ligament with the anterior horn of the lateral meniscus and its central tendinous attachments can give the appearance of a highsignal cleft within the meniscus on sagittal images. ${ }^{(10)}$ Pseudotears of the anterior horn of the lateral meniscus are seen in $22 \%-38 \%$ of MR imaging examinations of the knee due to the course of the intermeniscal ligament. ${ }^{(11)}$ In reality, isolated tears of the anterior horn of the lateral meniscus are relatively rare and account for only $16 \%$ of lateral meniscal tears. ${ }^{(5)}$

Similarly, normal anatomic interfaces may also mimic meniscal tears in the case of the posterior intermeniscal ligament (Fig. 8), as seen in this separate case (Fig. 9). However, such abnormal signal intensity changes can be distinguished from meniscal tears by careful delineation of the normal anatomic structures on consecutive MR images in orthogonal imaging planes. ${ }^{(5)}$ Other normal anatomical structures that may mimic meniscal tears include meniscofemoral ligaments, as alluded to earlier, and the popliteus tendon as it passes posterior to the posterior horn of the lateral meniscus, causing a pseudotear appearance at the popliteal hiatus. ${ }^{(12)}$ These structures, however, fall outside the scope of this paper.

In conclusion, one must be aware of the MM ligament variants of the knee during MR imaging, as they can mimic meniscal tears. By tracing these ligaments along their entire course from origin to insertion, these variants can be correctly identified, using the normal morphology of the adjacent meniscus as further supporting evidence.
ABSTRACT A 29-year-old man with a previous football injury to his left knee presented with pain of the same knee. The patient twisted it as he was turning a corner quickly while going up the stairs, leading to internal rotation of his femur on his tibia with his knee in flexion. MR imaging revealed a bucket-handle tear of the medial meniscus, as well as a complete tear of the anterior cruciate ligament. However, image interpretation was complicated by the presence of a medial oblique meniscomeniscal ligament, a rare normal variant among intermeniscal ligaments of the knee. All four recognised variants of intermeniscal ligaments are discussed, with emphasis on their prevalence, imaging and anatomical features, and the way in which they may mimic meniscal tears.

Keywords: bucket-handle, intermeniscal ligament, meniscal tear, meniscomeniscal ligament

\section{REFERENCES}

1. Zivanović S. Menisco-meniscal ligaments of the human knee joint. Anat Anz $1974 ; 135: 35-42$

2. Dervin GF, Paterson RS. Oblique menisco-meniscal ligament of the knee. Arthroscopy 1997; 13:363-5.

3. Sanders TG, Linares RC, Lawhorn KW, Tirman PF, Houser C. Oblique meniscomeniscal ligament: another potential pitfall for a meniscal tear-anatomic description and appearance at MR imaging in three cases. Radiology 1999; 213:213-6.

4. Chan CM, Goldblatt JP. Unilateral meniscomeniscal ligament. Orthopedics 2012; 35:e1815-7.

5. Mohankumar R, White LM, Naraghi A. Pitfalls and pearls in MRI of the knee. AJR Am J Roentgenol 2014; 203:516-30.

6. Singson RD, Feldman F, Staron R, Kiernan H. MR imaging of displaced buckethandle tear of the medial meniscus. AJR Am J Roentgenol 1991; 156:121-4.

7. Camacho MA. The double posterior cruciate ligament sign. Radiology 2004; 233:503-4

8. Soames RW. Skeletal system. In: Williams PL. Gray's Anatomy: The Anatomical Basis of Medicine and Surgery, 38th edition. Edinburgh: Churchill Livingstone, 1995: 703-4

9. Nelson EW, LaPrade RF. The anterior intermeniscal ligament of the knee. An anatomic study. Am J Sports Med 2000; 28:74-6.

10. Erbagci H, Yildirim H, Kizilkan N, Gümüsburun E. An MRI study of the meniscofemoral and transverse ligaments of the knee. Surg Radiol Anat 2002; 24:120-4.

11. Watanabe AT, Carter BC, Teitelbaum GP, Seeger LL, Bradley WG Jr. Normal variations in MR imaging of the knee: appearance and frequency. AJR Am J Roentgenol 1989; 153:341-4.

12. De Smet AA. How I diagnose meniscal tears on knee MRI. AJR Am J Roentgenol 2012; 199:481-99. 


\section{SINGAPORE MEDICAL COUNCIL CATEGORY 3B CME PROGRAMME} (Code SMJ 201705B)

Question 1. Regarding meniscomeniscal (MM) ligaments of the knee:

(a) Oblique MM ligaments are named based on their anterior attachment site.

(b) They are commonly torn in association with meniscal injuries.

(c) They are attached by fibres to the anterior cruciate ligament.

(d) They possess signal intensity similar to the meniscus on magnetic resonance (MR) imaging.

Question 2. Regarding the double posterior cruciate ligament (PCL) sign:

(a) It is highly specific for a bucket-handle tear of the labrum.

(b) It is associated with the congenital presence of two PCLs.

(c) A potential pitfall is the ligament of Humphry.

(d) A potential pitfall is the popliteus tendon.

Question 3. Regarding MM ligaments of the knee:

(a) There are two variants of the oblique MM ligaments.

(b) The medial oblique MM ligament is attached to the anterior horn of the medial meniscus and the posterior horn of the lateral meniscus.

(c) The medial oblique MM ligament is synonymous with the ligament of Humphry.

(d) The lateral oblique MM ligament is attached to the posterior horn of the medial meniscus and the anterior horn of the lateral meniscus.

Question 4. Regarding MM ligaments of the knee:

(a) The medial oblique MM ligament is the most common variant.

(b) Intermeniscal ligaments have high signal intensity on MR imaging.

(c) Oblique MM ligaments have a combined frequency of $1 \%-4 \%$.

(d) The lateral oblique MM ligament is more common than the posterior intermeniscal ligament.

Question 5. Regarding transverse intermeniscal ligaments of the knee:

(a) Nelson and LaPrade described three different types based on their attachment.

(b) Nelson and LaPrade described three different types based on their orientation.

(c) The anterior intermeniscal ligament can be mistaken for a tear in the anterior horn of the lateral meniscus on MR imaging.

(d) The posterior variant is more common than the anterior variant.

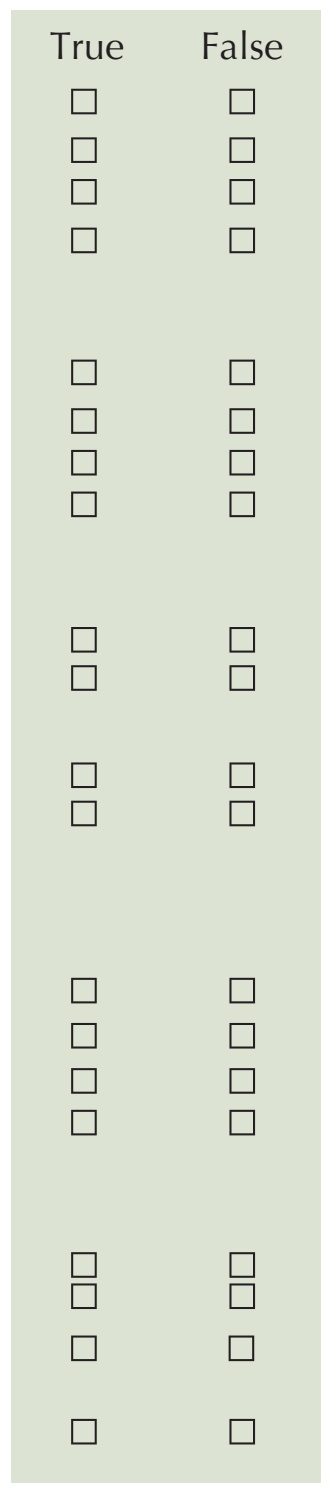

\footnotetext{
Doctor's particulars:

Name in full

MCR number

Specialty:

Email address

\section{SUBMISSION INSTRUCTIONS:}

(1) Visit the SMJ website: http://www.smj.org.sg/current-issue and select the appropriate set of questions. (2) Provide your name, email address and MCR number. (3) Select your answers and click "Submit".

\section{RESULTS:}

(1) Answers will be published online in the SMJ July 2017 issue. (2) The MCR numbers of successful candidates will be posted online at the SMJ website by 30 June 2017. (3) Passing mark is $60 \%$. No mark will be deducted for incorrect answers. (4) The SMJ editorial office will submit the list of successful candidates to the Singapore Medical Council. (5) One CME point is awarded for successful candidates.

Deadline for submission: (May 2017 SMJ 3B CME programme): 12 noon, 23 June 2017.
} 